\title{
Evaluation of tetracycline, oxytetracycline and penicillin $G$ residues in chicken meat samples by high performance liquid chromatography with pda detection
}

\author{
Fatoş Ayça ÖZDEMIR OLGUN ${ }^{1, *}$ Birsen DEMIRATA ÖZTÜRK ${ }^{1}$ \\ ${ }^{1}$ Istanbul Technical University, Faculty of Science and Letters, Department of Chemistry, Maslak, Sariyer, Istanbul, \\ Turkey
}

\begin{abstract}
Penicillin G, tetracycline and oxytetracycline are broad-spectrum antibiotics with considerably low side effects which are used in most of the poultries. Due to complex matrix effects, it is considerably difficult to isolate these compounds from other molecules (such as proteins and lipids) in order to analyze. In this study, a high performance liquid chromatography (HPLC) coupled with photodiode array (PDA) detector system was introduced for the determination of tetracycline, oxytetracycline and penicillin $\mathrm{G}$ residues in nine chicken breast samples. For the separation of tetracycline and oxytetracycline out of samples prior to the analysis, trichloroacetic acid (TCA) and McIlvaine buffer solutions were used while formic acid and phosphate buffer solutions were utilized for penicillin $\mathrm{G}$ using a solid phase extraction system. The peaks at the chromatograms were enlightened and recovery percentages were calculated using spiked samples $(96.57 \%$ for penicillin G; $99.00 \%$ for oxytetracycline; $95.92 \%$ for tetracycline). LOD and LOQ values were calculated, respectively as $1.55 \mu \mathrm{gL}^{-1}$ and $5.20 \mu \mathrm{gL}$ ${ }^{1}$ for tetracycline; $1.32 \mu \mathrm{gL}^{-1}$ and $4.39 \mu \mathrm{gL}^{-1}$ for oxytetracycline; $1.07 \mu \mathrm{gL}^{-1}$ and $3.60 \mu \mathrm{gL}^{-1}$ for penicillin G. With the proposed method, the determination of three antibiotic residues was performed in less than 15 minutes and applied successfully to real samples.
\end{abstract}

\section{Article info}

History:

Received:20.04.2020

Accepted:04.08.2020

Keywords:

Antibiotic residue,

analysis,

hplc-pda,

solid phase extraction.

\section{Introduction}

Chicken meat is one of the most consumed meat products around the world, with its low-cost, high protein content and health-friendly properties [1]. Antibiotics are the compounds synthesized through bacteria or fungicide and employed for the medical treatments such as chemotherapeutic and prophylactic properties [2]. The first antibiotic treatment in animals was at 1940s for medical issues [3]. However, once their effects on growth and feed efficiency were discovered, chicken meat production industry accelerated their usage. Taking the advantage of anabolic effects of antibiotics, caused bacteria resistance both at animals and humans consuming animal products of these animals. Therefore, at the beginning of 1970s, European Union started to control these substances regarding to the maximum amount of metabolites (originated from veterinary pharmaceuticals) found in a food product, defined as maximum residue limits (MRL). There are many reasons to monitor residues of antibiotics in animal products as; excess usage of antibiotics, marketing and slaughter of animals after a short time period of medical treatment, taking maximum efficiency by mixing the feed with antibiotics or misusage. Whatever the reason is, MRL of antibiotics found in animal products should be determined and evaluated with respect to regulations [4]. Most commonly used antibiotics in poultries are penicillin $\mathrm{G}$, tetracycline and oxytetracycline that are broad-spectrum antibiotics with considerably low side effects [5,6]. Microbial or immunological assays seem to be the most preferred methods for monitoring MRL in meat samples, as they are low-cost and fast. However, the most important drawback is that they are too specific on one target analyze. There have been several studies on the determination of antibiotics in animal products using various methods such as LC, LC-MS/MS, HPLC and HPLC with fluorescence detection [7-12]. Liquid chromatographic methods with their simultaneous seperation and minimum matrix effects especially in 
drug analyses, are the most preferred analytical techniques [13].

Sample preparation step is the most important part of providing a promising and accurate method in complex matrixes such as meat. Poultry meat, just as other meat samples, contain high amount of protein and lipid making the extraction part of the target molecules challenging [14]. Among many procedures, liquid extraction in combination with solid phase extraction (SPE) system was utilized, as it is suitable for tetracycline, oxytetracycline and penicillin $G$ and ensures the accuracy.

In this study, determination of tetracycline, oxytetracycline and penicillin $G$ by HPLC-PDA method with photo diode array detection system enabling to monitor both chromatogram and spectrum of a sample was used to analyze antibiotic residues in nine chicken breast samples. Solid phase extraction system was used to isolate the antibiotics out of real samples. Limit of detection, limit of quantification, recovery percentages were calculated in order to validate the method.

\section{Materials and Methods}

\subsection{Chemicals and apparatus}

Standards of tetracycline, oxytetracycline and penicillin $\mathrm{G}$ were all purchased from Aldrich. HPLCgrade solutions such as methanol, acetonitrile with citric acid monohydrate and ammonium acetate were purchased from E. Merck. J.T. Baker's oxalic aciddihydrate, trichloroacetic acid, disodiumhydrogen phosphate dihydrate, potassiumphosphate dibasic and potassium hydrogen phosphate were used for the experiments. Formic acid and Na salt of EDTA were purchased from Carlo Erba. During experiments, as it is required for the installation of HPLC, ultrapure water was used.

\subsubsection{Preparation of Solutions}

McIlvaine buffer solution $(\mathrm{pH}=4)$ was prepared dissolving $2.95 \mathrm{~g}$ of citricacidmonohydrate and $3.43 \mathrm{~g}$ disodiumhydrogen phosphate dihydrate and $8.41 \mathrm{~g}$ etilendiamintetraacetic acid sodiumsalt in $250 \mathrm{~mL}$ ultra-pure water [15].

Phosphate buffer solution $(\mathrm{pH}=8.5)$ was prepared dissolving potassiumphosphate dibasic in $250 \mathrm{~mL}$ ultra-pure water.

Solutions to be used in sample preperation step were prepared as follows; $20 \%$ (w/v) TCA solution, 5\% $(\mathrm{v} / \mathrm{v}) \mathrm{MeOH}$ solution, $0.1 \%(\mathrm{v} / \mathrm{v})$ formic acid solution, $0.03 \mathrm{M}$ methanolic oxalic acid solution, $0.025 \mathrm{M}$ $\mathrm{KH}_{2} \mathrm{PO}_{4}$ solution.
Stock solutions of tetracycline, oxytetracycline and penicillin $\mathrm{G}$ at $1000 \mathrm{mgL}^{-1}$ concentration levels were prepared in methanol and standard solutions at desired concentration levels were obtained by appropriate dilutions.

\subsection{Sample preperation by solid phase extraction (SPE) system}

Eight chicken breast samples of the most popular companies were purchased from local markets found in Istanbul, Turkey. The organic chicken breast sample was purchased from a local poultry farm found in a village of Catalca, Turkey. The samples were labeled with capital letters (from A to I) for a better understanding. Raw meat samples were minced with mechanic blender. For tetracycline and oxytetracycline; $2.0 \mathrm{~mL}$ of $20 \%$ TCA buffer solution and $20.0 \mathrm{~mL}$ Mcllavaine buffer solution were added on the homogenized meat samples at $5.0 \pm 0.1 \mathrm{~g}$ weight, respectively and allowed to mix for $5 \mathrm{~min}$. using vortex mixer. The mixtures were centrifuged for $15 \mathrm{~min}$ at $3500 \mathrm{rpm}$ and purified using SPE system [15]. C18 cartridge was washed with $10 \mathrm{~mL}$ of $5 \%$ methanol solution before extraction and the analytes were eluted using $0.01 \mathrm{M}$ methanolic oxalic acid solution. The solvent of the final solution was evaporated with rotary and the residue was dissolved in $2.5 \mathrm{~mL}$ methanol, filtered through $0.45 \mathrm{~mm}$ PTFE membrane filters in order to be analyzed with HPLC.

For Penicillin G, $2.0 \mathrm{~mL} \mathrm{20 \%} \mathrm{formic} \mathrm{acid} \mathrm{and} 20.0 \mathrm{~mL}$ pH8.5 phosphate buffer solutions were added to the minced raw chicken breast samples and mixed for 5 min with the aid of homogenizer. The mixture was centrifuged for $15 \mathrm{~min}$ at $3500 \mathrm{rpm}$. and extracted using SPE system equipped with $\mathrm{C} 18$ cartridge that was washed with $3.0 \mathrm{~mL}$ methanol and $3.0 \mathrm{~mL}$ of $0.1 \%$ formic acid prior and latter to extraction process. Peniciline $\mathrm{G}$ was eluted with $3.0 \mathrm{~mL}$ acetonitrile and solvent was evoporated using rotary. The residue was dissolved in $2.5 \mathrm{~mL}$ methanol and filtered through 0.45 $\mu \mathrm{m}$ filter to prevent any possible blockage at HPLC tubing systems.

\subsection{HPLC-PDA technique}

For the determination of antibiotics, two different gradient elution programs were developed and carried out. For tetracycline and oxytetracycline, the mobile phase consisted of HPLC-grade methanol (mobile phase A), HPLC-grade acetonitrile (mobile phase B) and $0.03 \mathrm{M}$ oxalic acid solution (mobile phase $\mathrm{C}$ ). Penicillin $G$ analysis with HPLC technique was performed using a different elution program involving $50 \% \mathrm{KH}_{2} \mathrm{PO}_{4}(\mathrm{~A})$ and HPLC-grade acetonitrile (B). 
The injection volume and flow rate were kept at $20 \mu \mathrm{L}$ and $1 \mathrm{mLmin}^{-1}$, respectively. The column temperature was set to $30^{\circ} \mathrm{C}$ for a stable procedure of analysis. The antibiotics may be determined at their own maximum absorption wavelength in agreement with the principle of diode array detector system, however for the mutual evaluation, the wavelength was adjusted to $351 \mathrm{~nm}$.

Calibration equations were obtained by graphing concentration values versus peak area. For the validation of the developed methods, the experiments were performed as three replicates and validation parameters such as; regression coefficients, limit of detection (LOD) and limit of quantification (LOQ) levels with recovery percentages were calculated.

\section{Results and Discussion}

\subsection{Determination of tetracycline, oxytetracycline and penicillin $G$ by conventional HPLC-PDA technique}

As cited in literature and observed through experiments, it is a difficult task to monitor all three antibiotics in a chromatogram due to intricate molecular structure of tetracycline [16]. Therefore another different gradient elution program was installed individually for penicillin G. Isocratic elution program with acetonitrile and methanol is the other option for elution, however it was proved to be inefficient resulting chromatograms with indefinite retention times and asymmetric peaks (with tails). The main reason of the peak asymmetry was explained with chelat formation of antibiotics (especially tetracycline) with metal ions [17]. In order to avoid these consequences, a third mobile phase, whether oxalic acid or phosphoric acid was employed in elution programs. Evaluating these concerns, the method described in experimental section was developed and applied to standard and sample solutions. For each antibiotic standard solution linear calibration graphs were obtained. Analyzing the data acquired from the calibration graphs, molar absorption coefficients, linear range and calibration equations were found and tabulated in Table 1. Validation parameters such as limit of detection (LOD) and limit of quantification (LOQ) values were calculated as 3 times and 10 times of standard deviations of blank solutions, divided by the slope of each calibration graph, respectively.

Table 1. The performance characteristics obtained with respect to HPLC-PDA method

\begin{tabular}{cccccccc}
\hline Name & $\begin{array}{c}\text { Retention } \\
\text { Time }\end{array}$ & $\begin{array}{c}\text { Calibration graph } \\
\text { equation }\end{array}$ & $\begin{array}{c}\text { Regression } \\
\text { Coefficient }\end{array}$ & $\begin{array}{c}\text { Molar } \\
\text { absorption } \\
\text { coefficient }\end{array}$ & $\begin{array}{c}\text { Working } \\
\text { Range } \\
\left(\mathrm{mgL}^{-1}\right)\end{array}$ & $\begin{array}{c}\text { LOD } \\
\left(\mu \mathrm{gL}^{-1}\right)\end{array}$ & $\begin{array}{c}\text { LOQ } \\
\left(\mu \mathrm{gL}^{-1}\right)\end{array}$ \\
\hline $\begin{array}{c}\text { Tetra } \\
\text { cycline }\end{array}$ & $9.15 \pm 0.07$ & $\begin{array}{c}\mathrm{A}= \\
(1.00+1.27 \text { ctetracycli } \\
\mathrm{ne}) \times 10^{5}\end{array}$ & 0.98 & $1.27 \times 10^{5}$ & $10-160$ & 1.55 & 5.20 \\
$\begin{array}{c}\text { Oxy } \\
\text { tetra } \\
\text { cycline }\end{array}$ & $8.03 \pm 0.06$ & $\begin{array}{c}\mathrm{A}=\left(7.13+1.46 \mathrm{c}_{\text {oxyt }}\right. \\
\text { etracycline }) \times 10^{5}\end{array}$ & 1.00 & $1.46 \times 10^{5}$ & $10-160$ & 1.32 & 4.39 \\
$\begin{array}{c}\text { Penicilli } \\
\mathrm{n} \mathrm{G}\end{array}$ & $3.95 \pm 0.02$ & $\begin{array}{c}\mathrm{A}=(1.11+2.73 \\
\mathrm{c}_{\text {penicilineG }) \times 10^{5}}\end{array}$ & 1.00 & $2.73 \times 10^{5}$ & $10-160$ & 1.07 & 3.60 \\
\hline
\end{tabular}

Table 2. Recovery percentage levels of chicken breast sample not including antibiotic residue

\begin{tabular}{|c|c|c|c|c|c|c|}
\hline \multirow[b]{2}{*}{$\begin{array}{l}\text { Added } \\
\text { concentra } \\
\text { tion } \\
\text { of } \\
\text { standard } \\
\text { solution } \\
\left(\mathrm{mgL}^{-1}\right)\end{array}$} & \multicolumn{2}{|c|}{ Penicillin G } & \multicolumn{2}{|c|}{ Oxytetracycline } & \multicolumn{2}{|c|}{ Tetracycline } \\
\hline & $\begin{array}{c}\text { Found } \\
\text { concentration } \\
\left(\mathrm{mgL}^{-1}\right)\end{array}$ & $\begin{array}{c}\mathrm{R} \% \\
\text { (recovery } \\
\text { percentage) }\end{array}$ & $\begin{array}{c}\text { Found } \\
\text { concentration } \\
\left(\mathrm{mgL}^{-1}\right)\end{array}$ & $\begin{array}{c}\mathrm{R} \% \\
\text { (recovery } \\
\text { percentage) }\end{array}$ & $\begin{array}{c}\text { Found } \\
\text { concentration } \\
\left(\mathrm{mgL}^{-1}\right)\end{array}$ & $\begin{array}{c}\mathrm{R} \% \\
\text { (recovery } \\
\text { percentage) }\end{array}$ \\
\hline & & & & & $19.78 \pm 0.11$ & \\
\hline \multirow[t]{2}{*}{20} & $19.43 \pm 0.08$ & 97.15 & $19.83 \pm 0.06$ & 99.17 & & 98.90 \\
\hline & $38.53 \pm 0.12$ & & & & $39.10 \pm 0.10$ & \\
\hline \multirow[t]{2}{*}{40} & & 96.32 & $39.12 \pm 0.08$ & 97.82 & & 97.76 \\
\hline & $77.26 \pm 0.22$ & & & & & \\
\hline 80 & & 96.57 & $79.20 \pm 0.18$ & 99.00 & $76.74 \pm 0.15$ & 95.92 \\
\hline
\end{tabular}


The accuracy of the proposed assay was proved through recovery percentage calculation. For this purpose, the blank chicken breast sample (labeled as C) was spiked with standard solutions of tetracycline, oxytetracycline, penicillin $\mathrm{G}$ at $20 \mathrm{mgL}^{-1}, 40 \mathrm{mgL}^{-1}, 80$ $\mathrm{mgL}^{-1}$ concentration levels, after extraction step.

As displayed in Table 1 and Table 2, low LOD and LOQ values, high regression coefficients and recovery percentage levels approaching $100 \%$ define the accuracy and validation of the proposed method. The other factor defining the applicability of a method is its selectivity and easy operation. The proposed technique with no interference effects during analysis, may bring novelty to literature as accurate determination of antibiotic residues in chicken breast samples in a short period of time (12 min including column regeneration). Application of The Proposed Method To Real

\section{Samples}

Sample preparation is an important step for the success of an assay. Solid phase extraction, 2/3 times faster replying when compared to liquid-liquid extraction [18] was preferred for sample analysis. Moreover, SPE has many advantages as fast sample preparation decreasing total time of analysis, obtaining samples at desired concentration levels and achieving high recovery percentages. Tetracycline-type of antibiotics is classified in amphoteric group of drugs that makes them difficult to isolate from the biological matrix. Methanolic oxalic acid was resorted to come over this drawback. Sample preparation procedure was summarized and schemed in Fig. 1.

\section{$5.0 \mathrm{~g}$ chicken breast sample}

- For tetracycline and oxitetracycline;

- $2.0 \mathrm{~mL} 20 \% \mathrm{TCA}$ ve $2.00 \mathrm{~mL}$ Mcllavaine buffer solution - For Penicillin G;

- $2.0 \mathrm{~mL} 20 \%$ formic acid ve $20.0 \mathrm{~mL} \mathrm{pH:8.5}$ phosphate buffer

Centrifuged $15 \mathrm{~min}$ at $3500 \mathrm{rpm}$.

Purified with SPE

Evoporate solvent with rotary and solve the residue with methanol

Filter through $0.45 \mu \mathrm{m}$ PTFE inject to HPLC

Figure 1. The flow chart of sample preparation

The chromatograms were obtained and figured (Fig. 2, Fig. 3) after sample preparation procedure followed by adequate analysis program. The amounts of residue levels found (as 3 replicates) were tabulated in Table 3 with standard deviations.

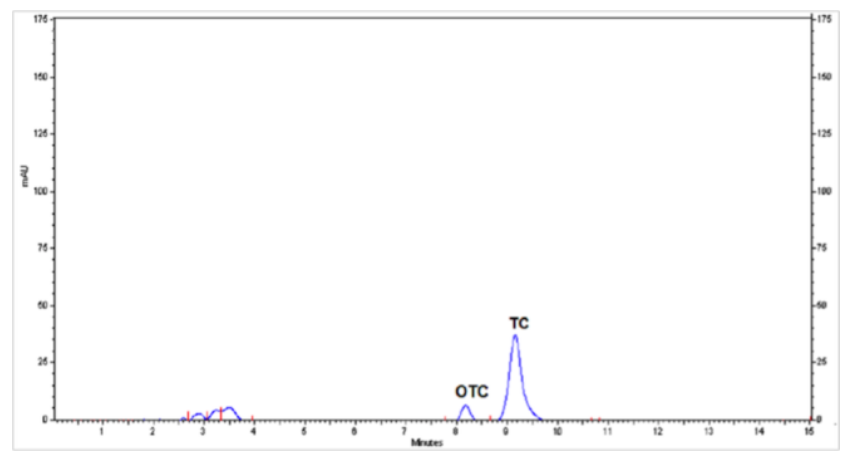

Figure 2. The chromatogram of sample $\mathrm{F}$ displaying peaks of oxytetracycline and tetracycline

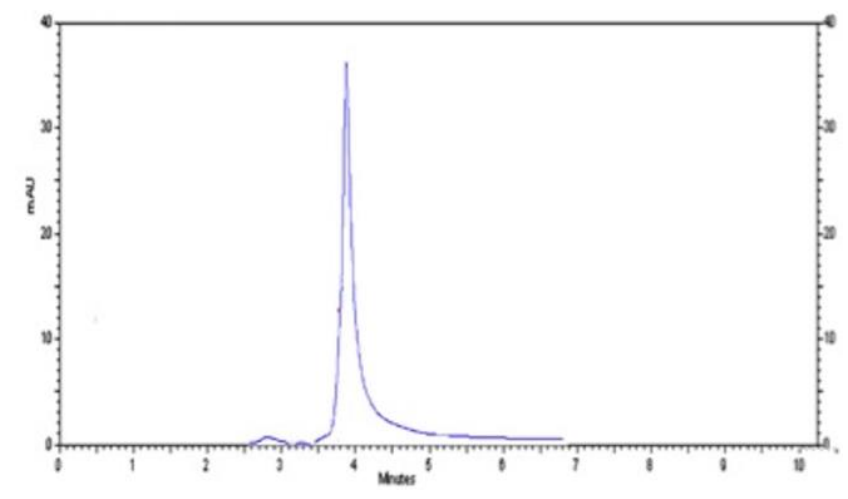

Figure 3. The chromatograms of sample F displaying peak Penicillin G

The peaks at the chromatograms of samples were identified with standard addition method and residue levels were quantified with the aid of calibration graphs. As shown in Table 3, 7 of 9 samples contain considerable amounts of antibiotic residues. Sample C that was purchased with organic label and $\mathrm{H}$ are the ones that do not include any type of antibiotic residue.

Amount of tetracycline and oxytetracycline were determined in raw chicken breast samples and compared with the limits of legislations. Penicillin G, which is also known as benzylpenicillin, was also investigated within this study. According to commission regulations on pharmacologically active substances and their classification regarding maximum residue limits in foodstuffs of animal origin, maximum residue levels should not exceed $100 \mu \mathrm{g}$ for tetracycline and oxytetracycline and $50 \mu \mathrm{g}$ for penicillin $\mathrm{G}$ at $1.0 \mathrm{~kg}$ chicken meat sample [19]. As it is displayed in Table 3, residue level of oxytetracycline seems to be over the limits while the others are approaching to the edge of limits. 
Table 3. Amount of oxytetracycline, tetracycline and Penicillin $\mathrm{G}$ found in $1.0 \mathrm{~kg}$ raw chicken breast samples

\begin{tabular}{cccc}
\hline Sample Name & Oxytetracycline $(\mu \mathrm{g})$ & $\begin{array}{c}\text { Tetracycline } \\
(\mu \mathrm{g})\end{array}$ & $\begin{array}{c}\text { Penicillin } \mathrm{G} \\
(\mu \mathrm{g})\end{array}$ \\
\hline A & $116.4 \pm 0.4$ & $56.6 \pm 0.3$ & $2.34 \pm 0.2$ \\
B & $19.5 \pm 0.5$ & $10.6 \pm 0.4$ & - \\
C & - & - & - \\
D & $6.2 \pm 0.2$ & - & - \\
E & - & $4.1 \pm 0.1$ & $1.74 \pm 0.1$ \\
F & $0.8 \pm 0.2$ & $14.8 \pm 0.6$ & $38.0 \pm 0.5$ \\
G & - & - & $28.4 \pm 0.4$ \\
H & - & - & - \\
I & $8.7 \pm 0.6$ & - & - \\
\hline
\end{tabular}

\section{Conclusion}

Antibiotics may be used in poultries not only for medical issues but also for feed efficiency and acceleration in growth. Unrelated with the main purpose, excess amount of antibiotic residue in meat products to be consumed is a major problem. Therefore, maximum residue levels must be evaluated. In this assay, a new method for the determination of antibiotic residue levels found in raw chicken meat, with easy-to-operate and effective sample preparation step, was introduced. The method was validated by calculating LOD, LOQ levels (LOD=1.07; LOQ=3.60 for Penicillin G) and recovery percentages and successfully applied to real samples. Determination of three most used antibiotics may be performed in less than 15 minutes.

When compared to the literature summarized in Table 4 , these LOD and LOQ values are quite sufficient as the method proposed in this study is very easy to install and cost-effective.

Table 4. Comparison of LOD and LOQ values found in the literature including the methods used and samples analyzed

\begin{tabular}{|c|c|c|c|c|c|c|c|c|}
\hline \multirow[t]{2}{*}{ Reference Number } & \multicolumn{2}{|c|}{ Oxytetracycline } & \multicolumn{2}{|c|}{ Tetracycline } & \multicolumn{2}{|c|}{ Penicillin G } & \multirow[t]{2}{*}{ Method } & \multirow[t]{2}{*}{ Sample } \\
\hline & LOD & LOQ & LOD & LOQ & LOD & LOQ & & \\
\hline [14] & $\begin{array}{c}3.0 \\
\mu \mathrm{gkg}^{-1}\end{array}$ & $10 \mu \mathrm{gkg}^{-1}$ & $\begin{array}{l}3.0 \mu \mathrm{gkg}^{-} \\
1\end{array}$ & $10 \mu \mathrm{gkg}^{-1}$ & - & - & $\begin{array}{l}\text { Turbo } \\
\text { Flow LC- } \\
\text { MS }\end{array}$ & $\begin{array}{c}\text { Chicken } \\
\text { meat }\end{array}$ \\
\hline [20] & $\begin{array}{c}0.1 \\
\mu \mathrm{gkg}^{-1}\end{array}$ & $1.0 \mu \mathrm{gkg}^{-1}$ & $0.1 \underset{1}{\mu \mathrm{gkg}^{-}}$ & $1.0 \mu \mathrm{gkg}^{-1}$ & $\begin{array}{c}0.5 \\
\mu \mathrm{gkg}^{-1}\end{array}$ & $\begin{array}{c}5.0 \\
\mu \mathrm{gkg}^{-1}\end{array}$ & $\begin{array}{l}\text { LC-MS- } \\
\text { MS }\end{array}$ & milk \\
\hline [11] & $\begin{array}{l}0.1 \\
\mu \mathrm{gkg}^{-1}\end{array}$ & - & $\begin{array}{c}0.3 \\
\mu \mathrm{gkg}^{-1}\end{array}$ & - & - & - & $\begin{array}{c}\text { HPLC- } \\
\text { couple } \\
\text { with } \\
\text { fluorescenc } \\
\text { e dedector }\end{array}$ & $\begin{array}{c}\text { commercia } \\
1 \text { tablets }\end{array}$ \\
\hline [17] & $\begin{array}{c}4.4 \\
\mu \mathrm{gkg}^{-1}\end{array}$ & $10 \mu \mathrm{gkg}^{-1}$ & $5.0 \underset{1}{\mu \mathrm{gkg}^{-}}$ & $13 \mu \mathrm{gkg}^{-1}$ & - & - & $\begin{array}{l}\text { HPLC- } \\
\text { DAD }\end{array}$ & $\begin{array}{l}\text { chicken } \\
\text { meat liver }\end{array}$ \\
\hline [21] & - & - & $\underset{1}{7.9 \mu \mathrm{gkg}^{-}}$ & $14.6 \mu \mathrm{gkg}^{-1}$ & - & - & LC-MS & $\begin{array}{c}\text { chicken } \\
\text { meat }\end{array}$ \\
\hline [22] & - & - & - & - & $\begin{array}{c}7.4 \\
\mu \mathrm{gkg}^{-1}\end{array}$ & $\begin{array}{c}24.6 \\
\mu \mathrm{gkg}^{-1}\end{array}$ & $\begin{array}{c}\text { Capillary } \\
\text { Electropho } \\
\text { resis }\end{array}$ & $\begin{array}{l}\text { chicken } \\
\text { muscle }\end{array}$ \\
\hline [23] & $5 \mu \mathrm{gkg}^{-1}$ & - & $5 \mu \mathrm{gkg}^{-1}$ & - & $\begin{array}{c}10 \mu \mathrm{gk} \\
\mathrm{g}^{-1}\end{array}$ & - & $\begin{array}{c}\text { LC-MS- } \\
\text { MS }\end{array}$ & $\begin{array}{c}\text { chicken } \\
\text { meat }\end{array}$ \\
\hline
\end{tabular}

\section{Conflicts of interest}

The authors state that did not have conflict of interests.

\section{References}

[1] Inal T., Besin hijyeni, hayvansal gıdaların sağlık kontrolu, Final Ofset, (1992) 55-57.
[2] Jayalakshmi K., Paramasivam M., Sasikala M., Tamilam T. V., Sumiho A., J. Entomol. Zool. Stud., 5 (2017) 1446-1451.

[3] Mitchel J., Griffiths M. W., Mceven W. B., Mcnab A. J., Yee A., Antimicrobial drug residues in milk and meat; causes, concerns, prevalence, regulations, tests and test performance, J Food Protect 61(6) (1988) 742-756. 
[4] EC (1990) Council Directive 90/167/EEC of 26 March 1990 laying down the conditions governing the preparation, placing on the market and use of medicated feeding stuffs in the Community, Council Directive 90/167/EEC (1990). Offic J Eur Comm L92:42-48

[5] Berrada H., Molto J.C., Manes J., Font G., Determination of Aminoglycoside and Macrolide Antibiotics in Meat by Pressurized Liquid Extraction and LC-ESI-MS., J Sep Sci., 33 (2010) 522-529.

[6] Percin Ozkorucuklu S., Uka B., Yildirim Bastemur G., Voltammetric Analysis of Cephalexin and Cefazolin in Pharmaceutical Formulations and Biological Samples., JOTSCA, 6(2) (2019) 217-224.

[7] Young-Song J., Jung Hu S., Joo H., Hwang J. B., Kim M. O., Shin J. K., Cho D., Determination of Penicillin Residues in Livestock and Marine Products by LC/MS/MS, WASET, 81 (2011) 809811.

[8] Granelli K., Brazzell C., Rapid multi-residue screening of antibiotics in muscle and kidney by liquid chromatography-electrospray ionizationtandem mass spectrometry, J.ACA., 585 (2007) 289-295.

[9] Furusawa N., Simplified liquid-chromatographic determination of residues of tetracycline antibiotics in eggs, Chromatographia, 53 (2001) 47-50.

[10] Schneider M. J., Braden S. E., Herrera I. R., Donoghue D. J., Simultaneous determination of fluoroquinolones and tetracyclines in chicken muscle using HPLC with fluorescence detection, $J$ Chromatography B, 846 (2007) 8-13.

[11] Lu H., Jiang Y., Li H., Chen F., Wong M., Simultaneous determination of oxytetra-cycline, doxycycline, tetracycline and chlortetracycline in tetracycline antibiotics by high-performance liquid chromatography with fluorescence detection, Chromatographia, 60(5-6), 259-264.

[12] Cháfer-Pericás C., Maquieira A., Puchades R., Fast screening methods to detect antibiotic residues in food samples, TrAC, 29 (9) (2010) 1038-1049.

[13] Yuvalı D., Narin İ., Simultaneous determination of sulfachloropyridazine and trimethoprim in veterinary formulations by hplc, Cumhuriyet Sci. J., 41(1) (2020) 239-244.

[14] Bousova K., Senyuva H., Mitterdorf K., Quantitative multi-residue method for determination antibiotics in chicken meat using turbulent flow chromatography coupled to liquid-chromatographytandem mass spectrometry, J. Chrom. A, 1274 (2013) 19- 27.

[15] Tong J., Rao Q., Zhu Z., Jiang Z., Ding S., Simultaneous determination of five tetracycline and macrolide antibiotics in feeds using HPCE, J. Sep. Sci., 32 (23-24) (2009) 4254-4260.

[16] Aszalos A., Fast determination of tetracycline antibiotics in different fast determination of tetracycline antibiotics in different media by HighPerformance Liquid Chromatography. Chromatographia, 20 (1985) 313-322.

[17] Shalaby A. R., Salama N. A., Abouraya S. H., Mehaya F. M., Incidence of tetracycline residues in chicken meat and liver retailed to consumers, Food Chem., 124 (2011) 1660-1666.

[18] Zief M., Solid Phase Extraction for Sample Preparation, Phillipsburg: JT Baker (2005).

[19] World Health Organization, 70th report of the Joint FAO/ WHO expert comittee on food additives, Geneva, 21-29 October (2008).

[20] Magon T., Silveira R., Galuch M. B., Fagan E. P., Feitoza F. D., Palombini S. V., Santos O. O., Visenteiner J. V., Simultaneous determination of four antibiotics in raw milk by UPLC-MS/MS using protein precipitation as sample preparation: Development, validation, and application in real samples, J. Braz. Chem. Soc., 29 (2018) 2441-2448.

[21] Cetinkaya F., Yibar A., Soyutemiz G. E., Okutan B., Ozcan A., Karaca M. Y., Determination of tetracycline residues in chicken meat by liquid chromatography-tandem mass spectrometry, Food Addit. Contann. Part B Surveill, 5 (2012) 9-45.

[22] Kowalski P., Koniecznna L., Determination of penicillin antibiotics in poultry muscle by capillary electrophoresis, Bull Vet Inst Pulawy, 51 (2007) 595-598.

[23] Jammoul A., Darra N., Evaluation of antibiotic residues in chicken meat samples in Lebanon antibiotics, Basel , 8 (2019) 69. 